\title{
Adolescent Exposure to the Synthetic Cannabinoid WIN 55212-2 Modifies Cocaine Withdrawal Symptoms in Adult Mice
}

\author{
María A. Aguilar *, Juan Carlos Ledesma *, Marta Rodríguez-Arias, Carles Penalva, \\ Carmen Manzanedo, José Miñarro and M. Carmen Arenas \\ Departamento de Psicobiología, Facultad de Psicología, Universitat de València, Avda. Blasco Ibáñez 21, \\ 46010 Valencia, Spain; marta.rodriguez@uv.es (M.R.-A.); carlespenalva@gmail.com (C.P.); \\ carmen.manzanedo@uv.es (C.M.); jose.minarro@uv.es (J.M.); carmen.arenas@uv.es (M.C.A.) \\ * Correspondence: asuncion.aguilar@uv.es (M.A.A.); juan.ledesma@uv.es (J.C.L.); Tel.: +34-96-3864611 (M.A.A.)
}

Received: 21 April 2017; Accepted: 16 June 2017; Published: 21 June 2017

\begin{abstract}
Chronic cannabinoid consumption is an increasingly common behavior among teenagers and has been shown to cause long-lasting neurobehavioral alterations. Besides, it has been demonstrated that cocaine addiction in adulthood is highly correlated with cannabis abuse during adolescence. Cocaine consumption and subsequent abstinence from it can cause psychiatric symptoms, such as psychosis, cognitive impairment, anxiety, and depression. The aim of the present research was to study the consequences of adolescent exposure to cannabis on the psychiatric-like effects promoted by cocaine withdrawal in adult mice. We pre-treated juvenile mice with the cannabinoid CB1 receptor agonist WIN 55212-2 (WIN) and then subjected them to a chronic cocaine treatment during adulthood. Following these treatments, animals were tested under cocaine withdrawal in the following paradigms: pre-pulse inhibition, object recognition, elevated plus maze, and tail suspension. The long-term psychotic-like actions induced by WIN were not modified after cocaine cessation. Moreover, the memory impairments induced by cocaine withdrawal were not altered by previous adolescent WIN intake. However, WIN pre-treatment prevented the anxiogenic effects observed after cocaine abstinence, and led to greater depressive-like symptoms following cocaine removal in adulthood. This study is the first to show the long-lasting behavioral consequences of juvenile exposure to WIN on cocaine withdrawal in adult mice.
\end{abstract}

Keywords: adolescence; cannabis; WIN 55212-2; cocaine withdrawal; mice

\section{Introduction}

Products of the hemp plant Cannabis sativa-marijuana and hashish are among the illicit substances most commonly used by adolescents and young adults worldwide, and are the world's third most popular recreational drug after ethanol $(\mathrm{EtOH})$ and tobacco [1]. Most cannabis users start in their mid-to-late teens, coinciding with major neuronal changes in the central nervous system [1]. The main psychoactive component of the Cannabis sativa plant and its derivatives is $\Delta 9$-tetrahydrocannabinol (THC), which acts primarily via specific endogenous cannabinoid 1 (CB1) receptors in the brain [2,3]. In recent years, synthetic cannabinoids have become very popular. Since 2008, over 160 synthetic cannabinoids have been detected in a range of different products that are sold as "legal" replacements for cannabis although they are considerably more toxic than marijuana and hashish [4]. Synthetic cannabinoids are also several times more potent than THC in activating cannabinoid receptors in the brain [5]. The endocannabinoid system is densely distributed in regions involved in the processing of emotional inputs, rewarding stimuli, habit formation, and higher cognitive functions, and represents a common neurobiological substrate for the addictive properties of different drugs of abuse via CB1 receptors [6,7]. 
Cannabinoid consumption, especially during pubertal development, induces long-lasting neurobehavioral alterations, psychiatric diseases (e.g., schizophrenia, depression, and anxiety disorders) and cognitive impairments in adulthood [8-10]. In experimental rodents, it has been demonstrated that chronic exposure to cannabinoid agonists during adolescence, but not adulthood, leads to neurobehavioral alterations in adult animals (for a review, see [11-13]). In particular, the administration of the synthetic CB1 agonist WIN 55212-2 (WIN) to rats and mice during the adolescent period leads to long-lasting deficits in different behavioral paradigms, such as fear conditioning [14,15], progressive ratio food self-administration [16] and pre-pulse inhibition of the acoustic startle response [14,16,17]. Other authors have reported that WIN-exposed rats show only increased acoustic startle latency, but not overt deficits in sensoriomotor gating or modifications of social interaction suggesting that exposure to WIN during adolescence does not lead to psychotic-like behavior [18]. Conversely, other authors have demonstrated that mice treated with WIN show an impairment in an attentional set-shifting task, supporting the notion that exposure to cannabinoids during adolescence may represent a risk factor for developing schizophrenia-like signs at adulthood [19]. Chronic pubertal WIN treatment also stimulates locomotion [17], increases novel-object exploration [18], induces depression-like behavior in the forced swim and sucrose preference tests [20] and alters anxiety-like behavior $[17,20]$. However, the effects of WIN on anxiety are in function of the paradigm used to evaluate anxiety. WIN reduces anxiety levels in the elevated plus-maze [17], but it induces anxiety-like behavior in the novelty-suppressed feeding test [20]. Moreover, treatment with WIN during adolescence impairs water maze performance [15] and object recognition memory [16], suppresses cortical oscillations (patterns of neural network activity implicated in cognitive processing) [21], and induces long-term depression in the nucleus accumbens [22]. Some studies have observed a recovery of cannabinoid-induced cognitive deficits. Chronic WIN administration during late adolescence induces an enduring impairment of hippocampal dependent short-term memory measured in the object location task, but the deficits in the water maze and the object recognition tasks as well as the impairment of long-term potentiation in the ventral subiculum-nucleus accumbens pathway are temporary [23]. A recent study confirms that the administration of WIN during adolescence acutely impairs short-term memory, but has no effect on working memory performance in adulthood [24]. In addition, this study reports an improvement in the performance of a delay-match-to-sample working memory task in adult rats self-administering WIN during adolescence [24]. Biochemical and structural brain alterations have also been reported after adolescent treatment with WIN, such as reductions in endocannabinoid signaling and mGluR5 in the hippocampus [14], higher hippocampal anandamide levels [15], an increased turnover of striatal dopamine (but with unchanged dopamine levels) [18], higher number of active dopaminergic neurons in the ventral tegmental area [19], serotonergic hypoactivity in the dorsal raphe and noradrenergic hyperactivity in the locus coeruleus [20], impaired maturation of prefrontal GABAergic transmission [25], loss of dendritic spine density in the dentate gyrus [26], and frontostriatal gliogenesis [18].

Interestingly, an important long-lasting consequence of cannabis use during adolescence is a heightened risk of developing other addictive diseases in adulthood. It has been reported that early onset and higher frequency of cannabis consumption is a reliable predictor of later problematic abuse of other illicit drugs in adulthood [27]. This is known as the "gateway hypothesis", which states that a causal relationship exists between early exposure to drugs of abuse and the subsequent abuse of other addictive substances later in life $[11,28,29]$. In animal models, the exposure of WIN during adolescence also affects the response to drugs of abuse at adulthood. For example, rats treated with WIN during adolescence showed a long-term reduced activation of midbrain dopaminergic neurons in response to morphine, cocaine and amphetamine [30]. However, other studies reported an increase of amphetamine-induced psychomotor sensitization [19], while others have not found an influence of adolescent WIN exposure on neurochemical and behavioural effects of amphetamine [31]. Similarly, previous studies of our laboratory with adolescent mice demonstrated that WIN pre-exposure strengthens the rewarding properties of 3,4 methylenedioxymetamphetamine (MDMA) and favors reinstatement of the craving for this drug [32]. The administration of WIN during adolescence 
can even induce transgenerational effects since offspring of female rats treated with WIN during adolescence (but not during pregnancy) exhibited greater sensitivity to the conditioned rewarding effects of morphine [33] as well as an increased sensitization to morphine-induced hyperactivity and higher levels of mu opioid receptor in the nucleus accumbens [34]. Regarding cocaine, the most widely used illicit drug in developed countries after cannabinoids, it has been demonstrated that the development of addiction to cocaine is strongly correlated with an early history of cannabis abuse in adolescence [35-37], which is also in accordance with the gateway hypothesis. In animal models, WIN administration during adolescence increases the rewarding effects of cocaine in mice [38]. Cocaine addiction is a chronic behavioral disturbance characterized by compulsive intake and relapse after short periods of abstinence [39]. Abuse of this substance and its subsequent withdrawal can cause psychiatric symptoms, among which psychosis, cognitive impairment, anxiety, and depression prevail [40-44]. However, although a link has been said to exist between cannabis consumption earlier in life and later development of cocaine addiction, there are no studies that have examined the behavioral outcomes of this pattern of drug ingestion in animals.

Therefore, the aim of the present study was to evaluate the effect of adolescent exposure to WIN on the psychiatric-like actions evoked by cocaine withdrawal. For this purpose, we pre-treated juvenile mice chronically with WIN and then submitted them to a chronic cocaine treatment during adulthood. Given that it has been established that periadolescent cannabis abuse has long-lasting psychiatric consequences, we tested the effect of these treatments on psychotic-, cognitive-, anxiety-, and depressive-like symptoms, in adult mice following cocaine withdrawal. Locomotor activity of mice was also tested. The results derived from the present research highlight the possible increased risk of developing some psychopathologies among subjects with an earlier history of cannabis abuse and cocaine consumption in adulthood.

\section{Results}

\subsection{Open Field}

None of our treatments had an effect on the locomotor activity of mice (Figure 1). The ANOVA did not show any significant effects of the Pre-treatment, the Treatment, or the Interaction Treatment X Pre-treatment.

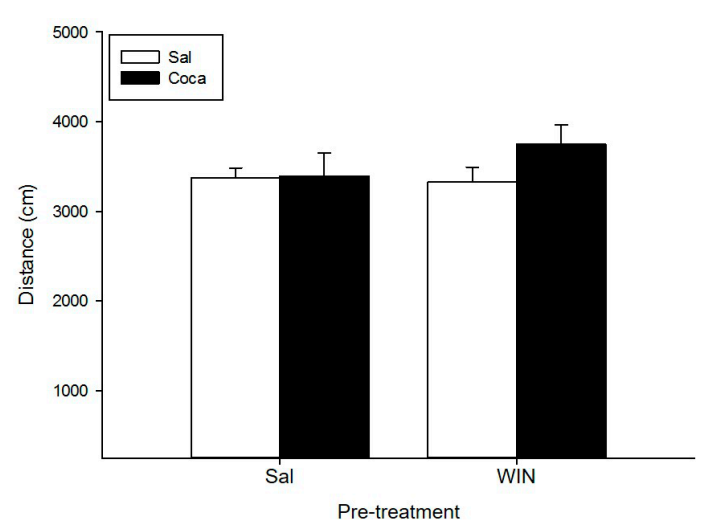

Figure 1. Effect of WIN 55212-2 administration during adolescence on locomotor activity after cocaine withdrawal in adulthood. Over post-natal day (PND) 34-47 (adolescence), mice ( $n=10$ per group) were pre-treated with physiological saline (Sal) or WIN 55212-2 (WIN $0.5 \mathrm{mg} / \mathrm{kg}$ given once daily). In adulthood (21 days later) they were treated with Sal or cocaine (Coca) in three daily injections separated by a 60-min interval according to the ensuing regime: $5 \mathrm{mg} / \mathrm{kg}$ on PND 68 and $69,15 \mathrm{mg} / \mathrm{kg}$ from PND 70 to 72, a two-day abstinence period, and $25 \mathrm{mg} / \mathrm{kg}$ from PND 75 to 79 . Animals were tested on PND 80. Bars depict mean \pm standard error mean (SEM) locomotor activity (distance travelled in $\mathrm{cm} / 10 \mathrm{~min}$ ) for all drug treatment groups. 


\subsection{Pre-Pulse Inhibition}

The ANOVA performed to analyze the pre-pulse inhibition (Figure 2) revealed a significant effect of pre-treatment $(F(1,36)=66.81, p<0.01)$, thereby indicating that the $\%$ of PPI of the WIN pre-treated mice (i.e., WIN-Sal and WIN-Coca) was significantly lower than that of the Sal pre-treated groups (Sal-Sal and Sal-Coca). The variable treatment and the interaction treatment $\mathrm{X}$ pre-treatment were not significant.

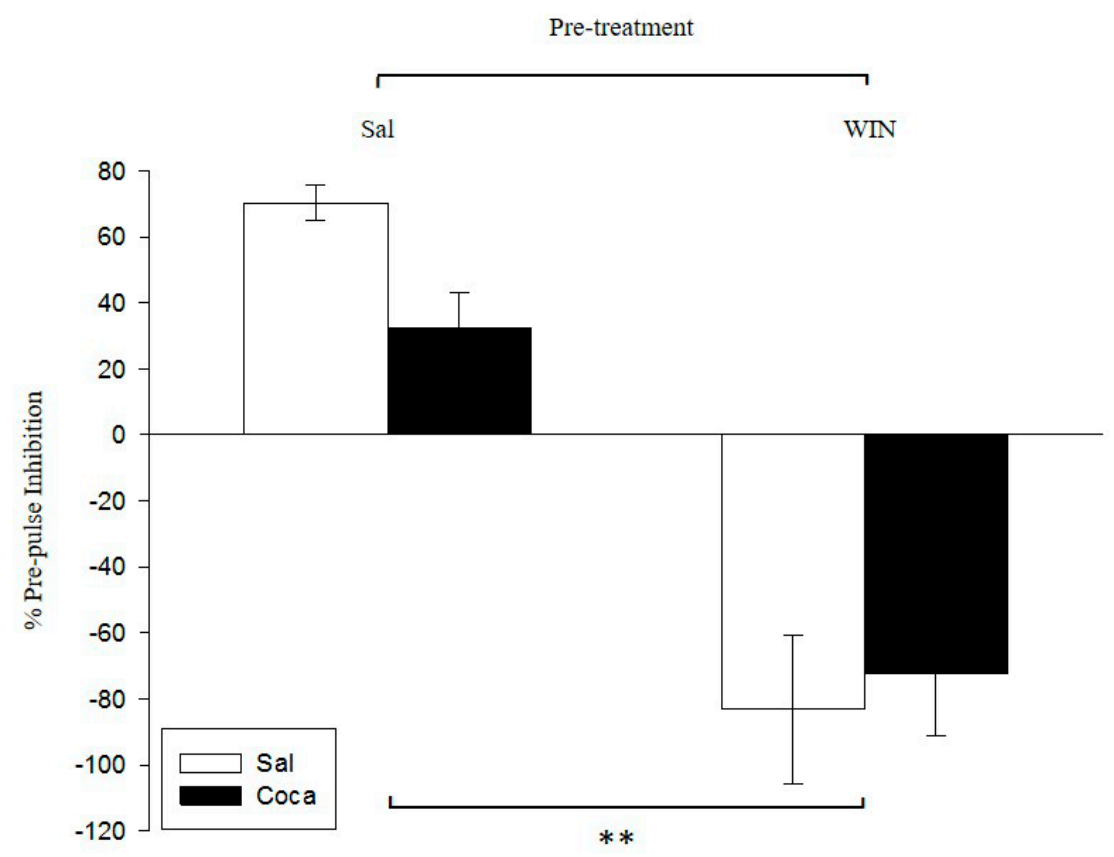

Figure 2. Effect of WIN 55212-2 administration during adolescence on pre-pulse inhibition after cocaine withdrawal in adulthood. Over PND 34-47 (adolescence), mice ( $n=10$ per group) were pre-treated with physiological saline (Sal) or WIN 55212-2 (WIN $0.5 \mathrm{mg} / \mathrm{kg}$ given once daily). In adulthood (21 days later) they were treated with Sal or cocaine (Coca) in three daily injections separated by a 60 -min interval according to the ensuing regime: $5 \mathrm{mg} / \mathrm{kg}$ on PND 68 and $69,15 \mathrm{mg} / \mathrm{kg}$ from PND 70 to 72 , a two-day abstinence period, and $25 \mathrm{mg} / \mathrm{kg}$ from PND 75 to 79 . Animals were tested on PND 81. Bars depict mean \pm SEM of percentage of the pre-pulse inhibition response for trials with a pre-pulse of $75 \mathrm{~dB}$ with inter-stimulus intervals of $100 \mathrm{~ms}$, and a pulse of $120 \mathrm{~dB}$ for all groups ( ${ }^{* *} p<0.01$ significant differences between Sal and WIN pre-treated mice).

\subsection{Object Recognition}

The ANOVA of the data for the object recognition (Figure 3) indicated a significant effect of Pre-treatment $(F(1,36)=6.29, p<0.05)$, and Treatment $(F(1,36)=15.11, p<0.01)$. The Tukey honest significant difference (HSD) post hoc test showed that the Discrimination Index (DI) of the Sal-Coca, the WIN-Sal, and the WIN-Coca groups was diminished in comparison with the Sal-Sal group $(p<0.05)$. No significant differences were encountered between the WIN-Sal and the WIN-Coca groups $(p>0.05)$. 


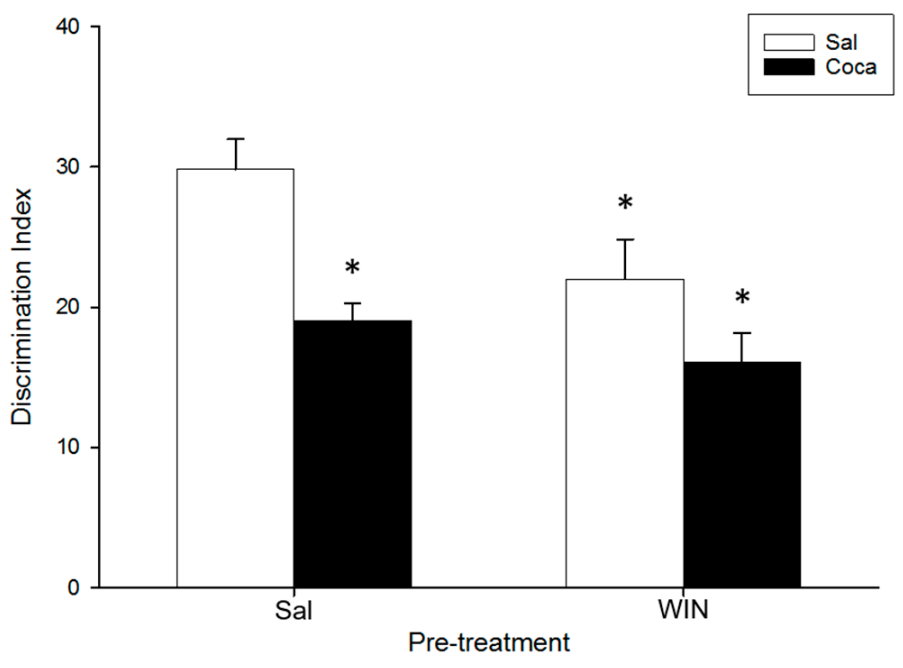

Figure 3. Effect of WIN 55212-2 administration during adolescence on novel object recognition after cocaine withdrawal in adulthood. Over PND 34-47 (adolescence) mice ( $n=10$ per group) were pre-treated with Sal or WIN ( $0.5 \mathrm{mg} / \mathrm{kg}$ given once daily). In adulthood ( 21 days later) they were treated with Sal or Coca in three daily injections separated by a 60-min interval according to the ensuing regime: $5 \mathrm{mg} / \mathrm{kg}$ on PND 68 and 69, $15 \mathrm{mg} / \mathrm{kg}$ from PND 70 to 72, a two-day abstinence period, and $25 \mathrm{mg} / \mathrm{kg}$ from PND 75 to 79. Animals were tested on PND 82. Bars depict mean \pm SEM of the Discrimination Index (DI) for all groups $\left({ }^{*} p<0.05\right.$ significantly different from the Sal-Sal group).

\subsection{Elevated Plus Maze}

Table 1 presents the results obtained in the elevated plus maze (EPM). The ANOVA for both the time that the animals spent in the open arms (Time OA), the percentage of time in the open arms (\% time OA), and the percentage of entries in the open arms that they performed (\% entries OA) revealed a significant effect of Pre-treatment $((F(1,36)=23.95, p<0.01),(F(1,36)=23.95, p<0.01)$, and $(F(1,36)=7.79, p<0.01)$, respectively $)$, Treatment $((F(1,36)=29.75, p<0.01),(F(1,36)=29.75$, $p<0.01)$, and $(F(1,36)=28.14, p<0.01)$, respectively $)$, and Interaction $((F(1,36)=33.16, p<0.01)$, $(F(1,36)=33.16, p<0.01)$, and $(F(1,36)=8.46, p<0.05)$, respectively). The post hoc test showed that Time OA, \% time OA, and \% entries OA were significantly lower in the Sal-Coca group than the rest of the groups $(p<0.01)$. For the number of entries that they carry out in the open arms (OA entries), the ANOVA found a significant effect of Treatment $(F(1,36)=15.66, p<0.01)$ and Interaction $(F(1,36)=8.85, p<0.01)$. Pairwise comparisons indicated that the Sal-Coca group carried out fewer OA entries than the other groups $(p<0.05)$. For the time spent in the closed arms of the maze (Time CA), the ANOVA exhibited a statistical effect of Pre-treatment $(F(1,36)=11.94, p<0.01$ ), Treatment $(F(1,36)=14.84, p<0.01)$, and Interaction $(F(1,36)=4.04, p<0.05)$. The post hoc test revealed that the Sal-Coca group spent more Time CA than the other groups $(p<0.01)$. For the number of entries in the closed arms (CA entries), the ANOVA reflected an effect of Pre-treatment and Treatment $(F(1,36)=8.84, p<0.01)$ and $(F(1,36)=6.94, p<0.05)$, respectively. The Tukey HSD test indicated that the Sal-Coca group performed more CA entries than the rest $(p<0.05)$. No significant differences were obtained between groups with respect to the total entries in both arms (Total entries) and the time remained in the center (Time center). 
Table 1. Effects of chronic adolescent WIN 55212-2 administration and cocaine withdrawal in adulthood on the elevated plus maze.

\begin{tabular}{ccccc}
\hline Measurement & Sal-Sal & Sal-Coca & WIN-Sal & WIN-Coca \\
\hline Time OA (s) & $97 \pm 4.7$ & $23 \pm 9.9^{* *}$ & $92 \pm 24$ & $93 \pm 28$ \\
$\%$ time OA & $32 \pm 1.6$ & $8 \pm 1^{* *}$ & $30 \pm 2.5$ & $31 \pm 3$ \\
OA entries & $23 \pm 2.2$ & $11 \pm 1.7^{*}$ & $21 \pm 1.1$ & $19 \pm 2.1$ \\
\% entries OA & $51 \pm 3$ & $25 \pm 4.1^{* *}$ & $51 \pm 3.4$ & $43 \pm 2.3$ \\
Time CA (s) & $130 \pm 13$ & $194 \pm 11^{* *}$ & $123 \pm 13$ & $133 \pm 13$ \\
CA entries & $24 \pm 2.6$ & $34 \pm 2.8^{*}$ & $20 \pm 2.6$ & $24 \pm 3.5$ \\
Total entries & $47 \pm 3.1$ & $45 \pm 2$ & $41 \pm 2.5$ & $43 \pm 3$ \\
Time center (s) & $67 \pm 9.2$ & $78 \pm 5.1$ & $71 \pm 4.9$ & $64 \pm 5.2$ \\
\hline
\end{tabular}

Across PND 34-47 (adolescence) mice ( $n=10$ per group) were pretreated with Sal or WIN $(0.5 \mathrm{mg} / \mathrm{kg}$ given once daily). In adulthood (21 days after) they were treated with Coca in three daily injections separated by a 60-min interval according to the ensuing regime: $5 \mathrm{mg} / \mathrm{kg}$ on post-natal day (PND) 68 and 69, $15 \mathrm{mg} / \mathrm{kg}$ from PND 70 to 72 , a 2-day abstinence period, and $25 \mathrm{mg} / \mathrm{kg}$ from PND 75 to 79 . Control mice received the same injections of saline. Elevated plus maze was carried out on PND 82. OA: open arms, CA, closed arms. ${ }^{*}$ and ${ }^{* *} p<0.05$ and 0.01 respectively, significantly different from the rest of the groups for each corresponding variable).

\subsection{Tail Suspension Test}

For the tail suspension test (Figure 4), the ANOVA indicated a significant effect of Pre-treatment $(F(1,36)=5.05, p<0.05)$ and Treatment $(F(1,36)=11.5, p<0.01)$. The Tukey HSD post hoc test indicated that the time spent immobile was higher in the WIN-Coca group in comparison to the rest $(p<0.05)$.

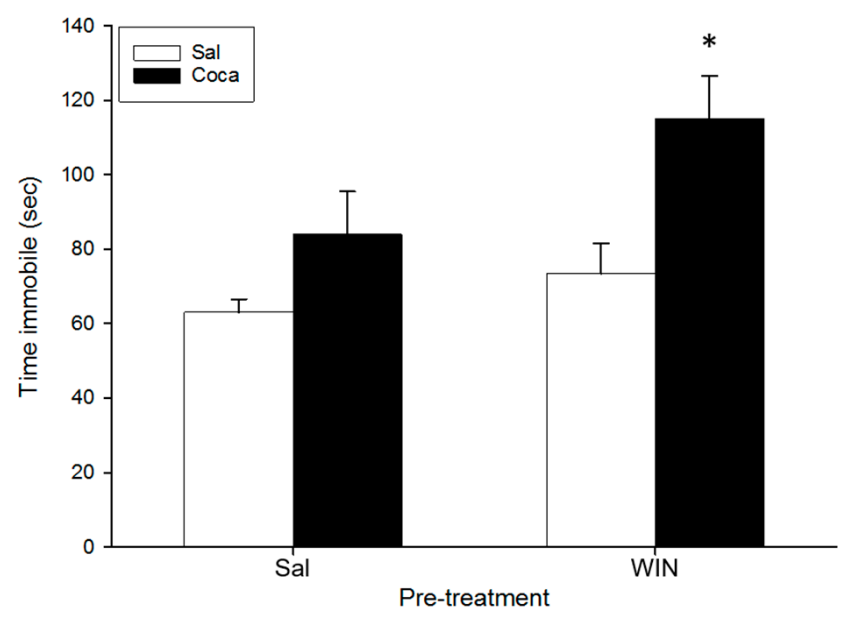

Figure 4. Effect of WIN 55212-2 administration during adolescence on the tail suspension test after cocaine withdrawal in adulthood. Over PND 34-47 (adolescence) mice ( $n=10$ per group) were pre-treated with Sal or WIN ( $0.5 \mathrm{mg} / \mathrm{kg}$ given once daily). In adulthood ( 21 days later) they were treated with Sal or Coca in three daily injections separated by a 60-min interval according to the ensuing regime: $5 \mathrm{mg} / \mathrm{kg}$ on PND 68 and 69, $15 \mathrm{mg} / \mathrm{kg}$ from PND 70 to 72, a two-day abstinence period, and $25 \mathrm{mg} / \mathrm{kg}$ from PND 75 to 79. Animals were tested on PND 83. Bars depict mean \pm SEM of the time (s) during which the mice remained immobile in the tail suspension test ${ }^{*} p<0.05$ significantly different from the rest).

\section{Discussion}

The results reported here represent a first approach towards assessing the long-lasting consequences of juvenile exposure to WIN on cocaine withdrawal in adult mice. We used a murine model of pubertal subchronic cannabis intake followed by a chronic cocaine binge regime in adulthood, thereby imitating a pattern seen in many human polydrug users [28,45]. A limitation of this study is the use of the synthetic CB1 cannabinoid agonist WIN instead of THC, which is the main psychoactive 
component of cannabis. However, there are several reasons for the use of WIN instead of THC. Firstly, in previous works of our laboratory on the influence of adolescent cannabinoid exposure on the rewarding effects of other drugs of abuse, we administered WIN following similar procedures (i.e., drug dose, treatment regime, strain and age of the subjects; see [32,38,46-48] for examples), thus giving us the possibility to compare the results obtained between the different studies. Secondly, the vehicle used to dissolve THC (a mixture of ethanol plus another solvent such as Cremophor) can induce behavioral side effects per se (unpublished data), while that of WIN (physiological saline with a low concentration $(<3 \%)$ of Tween 20$)$ is innocuous for mice [49]. Thirdly, WIN possesses higher affinity for cannabinoid CB1 and CB2 receptors than THC [5] and has been widely used to study the implication of the endocannabinoid system in different behaviors in rodents as well as in animal models of cannabinoid dependence [14-20,50]. In particular, WIN is self-administered by rodents [24,50] and induces cross-tolerance and cross-discrimination with THC [50]. Thus, any effects of THC on behavior are likely to be replicated by WIN. Therefore, although the effects of WIN would be more comparable to those of the abused synthetic cannabinoids (K2, Spice, etc.) than to those of cannabis [51], the use of WIN can contribute to clarifying the effects of adolescent cannabinoid exposure on the behavioral alterations induced by cocaine abstinence.

We have found that the long-term psychotic-like effects induced by WIN administration are not altered by cocaine abstinence. Furthermore, the short-term memory deficits evoked by cocaine are not modified after earlier administration of WIN, which itself induces a long-lasting memory impairment. Interestingly, we have shown that adolescent cannabinoid treatment prevents the anxiogenic effects observed after cocaine abstinence in adult mice. Finally, we observed that the combination of these treatments enhanced the risk of suffering from depressive-like symptoms. Additionally, in order to rule out any confounding factor in the rest of the behavioral results, we have confirmed that none of our pharmacological manipulations affect the spontaneous locomotor activity.

In the PPI paradigm, we observed that adult mice treated with WIN during adolescence showed an increase in sensorimotor gating. This outcome is in line with earlier reports, which have demonstrated that WIN administration only induces a long-term impairment of the PPI response when is given during the adolescent period $[14,16,17]$. Hence, it seems that cannabinoid consumption early in life raises the risk of suffering from schizophrenia, as was observed in human beings [52]. Conversely, we found no significant effects of cocaine abstinence in adult mice treated with saline during adolescence. These results, in the same line as previous studies with rats [53,54] and mice [55], suggest that cocaine withdrawal by itself does not induce psychotic-like actions. As can be seen in Figure 2, while the administration of WIN during adolescence clearly impairs PPI when the mice become adults (WIN-Sal group), there is a trend towards a reduction in the PPI of mice treated only with cocaine in adulthood when they are in abstinence (Sal-Coca group). Therefore, it could be plausible to hypothesize that the administration of both drugs will induce synergistic impairing effects on PPI, but it does not seem to be the case. Mice treated with the combination of WIN during adolescence and cocaine in adulthood showed a disruption of PPI similar to that observed in mice treated only with the cannabinoid agonist. This incongruity could be explained by a ceiling effect on the disruption of PPI induced by WIN exposure. In an earlier study, we demonstrated that exposure to an EtOH binge-drinking procedure during adolescence, which is not able to alter the PPI by itself, impairs the startle reflex in mice exposed to the same cocaine withdrawal as that of the current study [55]. This supports the notion that previous drug exposure during the adolescent period may enhance the putative psychotic-like actions of cocaine in mice. Further studies may be carried out to test this possibility, for example by modifying the PPI parameters such as the intensity and the duration of the pre-pulse, or by using different doses and timings of both WIN and cocaine delivery.

In the OR test, adolescent WIN pre-treatment disrupted short-term memory in adult mice treated with saline, in agreement with previous reports showing that chronic pubertal cannabinoid administration impairs the execution of this task in adult rodents $[16,56,57]$. Nevertheless, a more recent study shows that chronic adolescent administration of THC does not alter memory of adult 
rats [58]. A possible explanation for this discrepancy could be due to methodological differences between these studies. In relation to the effects of cocaine abstinence, we have found that mice treated with saline during adolescence undergoing withdrawal from cocaine in adulthood performed the OR task more poorly than control subjects (Sal-Sal group), that is in agreement with previous studies in rodents $[55,59,60]$. Similarly, mice pre-treated with WIN during adolescence undergoing cocaine withdrawal performed the OR task more poorly than the control subjects (Sal-Sal group). However, given that there were no differences in the DI between the WIN-Coca group and the WIN-Sal or Sal-Coca groups, we cannot conclude that WIN administration interacts with cocaine to enhance the cognitive deficits that both drugs produced by themselves. Notwithstanding, this is the first study to assess the effects of the possible interaction between the two treatments on cognitive function, and future research is needed to evaluate its effects on memory more thoroughly (for example by using schedules of WIN and cocaine administration that did not themselves impair recognition memory).

In the EPM, the means of the total entries and the time in center did not vary among the groups, thereby confirming that, as occurred in the OF, the locomotor activity of mice was not altered after our treatments. Moreover, we found that adolescent WIN administration did not affect the anxiety scores of adult mice. To date, the few studies evaluating the long-lasting effects of chronic cannabinoid administration on the behavior of adult rodents in the EPM have been performed in rats and have obtained controversial results. Pubertal WIN exposure reduced the anxiety of adult rats in one study [17] while adolescent THC treatment elicited anxiety-like effects in adult rats in another study [61]. Given that WIN is a synthetic derivative from THC, it may be possible that it does not act in the brain in exactly the same way as THC, thus leading to divergent results. Further research is needed to determine the long-lasting effects of cannabis and its derivatives on anxiety. With respect to the effects of cocaine abstinence, we demonstrated that cessation of cocaine administration in adult mice treated with saline during adolescence evoked anxiety-like behaviors, in agreement with earlier studies in rats [41,62-66] and mice [55]. However, a very interesting result of the present study is that the anxiety values displayed by the animals pre-treated with WIN and later with cocaine did not differ from those of control mice. It could be interpreted from this that juvenile exposure to WIN alleviates the anxiety withdrawal symptoms associated with cocaine abstinence in adult mice. Since high anxiety is one of the factors that contribute to relapse, because many cocaine-abstinent addicts consume the drug again to alleviate the anxiety induced by the withdrawal syndrome $[67,68]$, one can speculate that cannabinoid consumption in adolescence protects against cocaine relapse after its abstinence in adulthood. However, an alternative interpretation might be that prior exposure to WIN, by reducing the anxiogenic effects induced by cocaine cessation, maintains cycles of consumption and abstinence because subjects experience the aversive consequences of the abstinence syndrome to a lesser degree. Similar to the observed in the present research, we have previously proven that mice exposed to an EtOH-binge drinking procedure during adolescence do not exhibit anxiety-like effects after cocaine removal in adulthood [55]. This suggests that adolescent exposure to drugs such as alcohol or cannabis could be a factor that modulates the anxiety related with cocaine withdrawal. Hence, taking into account that it has been reported that periadolescent abuse of both alcohol and cannabis is a high predictor of later development of cocaine addiction $[27,29,35]$, it is possible that the alleviation of anxiety that results as a consequence of the earlier intake of these drugs may play an important role in the acquisition and maintenance of addiction to cocaine. This could be an appealing forthcoming line of research to be explored.

In the TST, depressive-like effects were not observed in adult mice treated with the cannabinoid agonist during adolescence. Studies evaluating the long-term consequences of adolescent cannabis exposure on depression-like behavior are scarce but a previous study showed that chronic WIN administration during adolescence led to a depression-like profile in the forced swim and sucrose preference tests in adult rats [20]. More research is therefore needed to determine the putative depressive-like properties of early cannabinoid exposure. Cocaine abstinence did not significantly increase immobility time with respect to the control group (Sal-Sal), in agreement with our previous 
study [55]. Some researchers have also found that abstinence from chronic cocaine did not induce any depression-like actions in rats using the sucrose preference or the forced swim tests [64], although in other studies cocaine withdrawal is accompanied by depression-like symptoms $[42,69,70]$. The tendency of cocaine to increase immobility scores was potentiated in abstinent mice pretreated with WIN during adolescence, since the WIN-Coca group showed a greater immobility time than the Sal-Coca group (and also than the WIN-Sal and Sal-Sal groups). Thus, it seems that a history of abuse of WIN during adolescence and cocaine discontinuation after its chronic intake at an adult age could predispose the subjects to suffer from depressive-like symptoms. A very similar result was obtained from a previous report from our laboratory, in which we demonstrated that adult mice under cocaine abstinence also exhibited a depressive profile in the TST, but only when being previously exposed to an EtOH binge-drinking treatment during the adolescent period [55]. Therefore, it seems that an earlier history of adolescent consumption of cannabis or EtOH might facilitate the development of later depressive disorders after cocaine abuse during adulthood.

\section{Materials and Methods}

\subsection{Animals}

Male mice of the OF1 strain purchased from Charles River (Barcelona, Spain) were used. The subjects were 21 days old upon arrival at the laboratory and were all housed under standard conditions in groups of four, at a constant temperature $\left(21 \pm 2{ }^{\circ} \mathrm{C}\right)$ and relative humidity $(60 \%)$, with a reversed light schedule (white lights on 19:30-7:30). Food and water were provided ad libitum throughout the study. All the procedures involving the mice and their care complied with national, regional, and local laws and regulations, which are in accordance with the Directive 2010/63/EU of the European Parliament and the Council of 22 September 2010 on the protection of animals used for scientific purposes. The protocol was approved by the Ethical Committee for Animal Experiments of the University of Valencia.

\subsection{Drugs}

All drugs were diluted in physiological saline $(\mathrm{NaCl} 0.9 \% w / v$; Sal) and injected intraperitoneally (IP). The selective CB1 receptor agonist WIN 55212-2 (WIN), obtained from Tocris Biogen Científica S.L. (Madrid, Spain), was dissolved in Sal mixed with two drops of Tween-80 (Sigma-Aldrich, Madrid, Spain), and dispensed at a dose of $0.5 \mathrm{mg} / \mathrm{kg}$. Cocaine hydrochloride (Coca) was supplied by Laboratorios Alcaliber S.A. (Madrid, Spain) and administered at doses of 5, 15, and $25 \mathrm{mg} / \mathrm{kg}$.

\subsection{Experimental Design}

On postnatal day (PND) 34, corresponding to early adolescence in humans [57], animals were injected with Sal or WIN once a day for 14 consecutive days. This dose of WIN was selected based on previous studies showing that it is able to modulate several behaviors in mice such as morphine- and MDMA-induced conditioned place preference, ingestive behavior, and EtOH consumption, among others [32,38,46,71-73]. After WIN pre-treatment, animals were untouched for three weeks, until cocaine administration began on PND 68, an age considered to represent adulthood in mice [56]. The procedure of cocaine administration was a variation of that described by [74], which has been proven to induce long-lasting alterations in rodent behavior [45,74]. In short, cocaine (or Sal administered at the same volume to control animals) was given to mice in ascending doses over a period of 12 days starting on PND 68, when they received three injections per day, separated by a $60 \mathrm{~min}$ interval, of either Sal or $5 \mathrm{mg} / \mathrm{kg}$ of cocaine (Coca 5) on PND 68 and 69, $15 \mathrm{mg} / \mathrm{kg}$ (Coca 15) on PND 70, 71, and 72 (followed by two-day period of abstinence), and $25 \mathrm{mg} / \mathrm{kg}$ (Coca 25) on PND 75, $76,77,78$, and 79. As a result, the following experimental groups were constituted: Sal-Sal: the control group, which received Sal throughout all the experimental phases; Sal-Coca: this group received Sal during the first phase (adolescence) and cocaine during the second (adulthood); WIN-Sal: this group 
was treated with WIN in adolescence and with Sal in adulthood; WIN-Coca: this group was injected with WIN during adolescence and with cocaine during adulthood.

\subsection{Behavioral Testing}

\subsubsection{Open Field}

The open field (OF) experiment was performed on PND 80 with the aim of assessing whether our pharmacological manipulations induced any unspecific effect on the normal spontaneous locomotor activity of mice that could have obscured the results obtained in the rest of the experiments. For that purpose, mice ( $n=10$ per group) were introduced individually into locomotor activity chambers consisting of a square arena $\left(30 \times 30 \times 35 \mathrm{~cm}^{3}\right)$ illuminated by a dim white light $(40 \mathrm{~lx})$. Horizontal locomotion was recorded as $\mathrm{cm}$ travelled in $10 \mathrm{~min}$ by a computerized video-tracking system. The movement of the mice inside the OP chamber was registered and transferred automatically to the computer using the software application Ethovision 2.0. (Noldus, Wageningen, The Netherlands).

\subsubsection{Pre-Pulse Inhibition}

Pre-pulse inhibition (PPI) of the acoustic startle response has been widely used as a measure of sensorimotor gating [75-77]. PPI is the normal reduction of the amplitude of the startle reflex in response to an intense startling stimulus (pulse, $>100 \mathrm{~dB}$ ) when this stimulus is shortly preceded by a weaker, non-startling sensory stimulus (pre-pulse, $<85 \mathrm{~dB}$ ). This paradigm has been used to explore the information-processing deficits that typically occur in subjects with psychosis, because human patients suffering from schizophrenia have PPI impairments [78,79]. It is a cross-species translational model that allows some features of schizophrenia to be studied $[76,80,81]$.

We used a PPI apparatus consisting of a Plexiglas tube $\left(28 \times 15 \times 17 \mathrm{~cm}^{3}\right)$ with a platform containing a sensor on its base, so that if the animal moves, the force exerted on the platform is detected. The movements caused by the startle are transduced by an accelerometer and the signal is recorded and digitized by a microcomputer that is also used to present the stimulus and collect the data. The unit is placed in a soundproofed chamber $\left(90 \times 55 \times 60 \mathrm{~cm}^{3}\right)$ that is constantly lit (lamp $10 \mathrm{w}$ ) and equipped with two $28-\mathrm{cm}$ speakers located $15 \mathrm{~cm}$ from the two sides of the Plexiglas box. These speakers are connected to an amplifier, which in turn is connected to a noise generator that manages the acoustic stimulus and a second noise generator that produces the signal corresponding to the pre-pulse. The apparatus (model CERS41, Computacisponse ciaitor (CERS41) Hardware ón Estimulador Registrador Startle Response) and program that collect the data were purchased from CIBERTEC, S.A. (Madrid, Spain).

The procedure, based on that used by van den Buuse [80], was carried out in two phases. The first was the acclimatization phase (on PND 80 ), in which mice ( $n=10$ per group) were placed in the animal holder for 5 min with a background noise of $65 \mathrm{~dB}$ but no startle stimuli. In the second phase (PND 81), after another 5-min acclimatization period, a series of trials were introduced in a pseudo-random order while the white noise kept playing in the background. The trials consisted of a startle pulse alone $(120 \mathrm{~dB})$, a pre-pulse alone $(75 \mathrm{~dB})$, and pulses with pre-pulse (pre-pulse of $75 \mathrm{~dB}$ with inter-stimulus intervals of $100 \mathrm{~ms}$ and a pulse of $120 \mathrm{~dB}$ ) with an inter-trials interval of $20 \mathrm{~s}$ and a duration of $4 \mathrm{~ms}$. The pre-pulse was introduced to verify that it was not acting as a pulse and to confirm that only the 120- $\mathrm{dB}$ pulse was acting as the main stimulus to induce the startle response in the animal. PPI was calculated as a percentage score: PPI $(\%)=100-($ startle response for pulse with pre-pulse $\times 100 /$ startle response for pulse alone).

\subsubsection{Object Recognition}

Object recognition (OR) tests episodic memory in rodents, is similar to methods used in clinical neuropsychology, and is considered a suitable model to investigate the effects of pharmacological manipulation on learning and memory [82]. It has been used as a measure of cognitive dysfunction 
according to deficits in object-context identification [83]. In the present study, it was performed in an open box $\left(24 \times 24 \times 15 \mathrm{~cm}^{3}\right)$ divided into four equally sized arenas by a sheet of cardboard. A video camera fixed to the ceiling enabled the four arenas to be visualized simultaneously. For the test, two types of objects were used: two small river stones and a small non-toxic plastic toy. This task consists of three phases: habituation, training session (T1), and test session (T2). In the habituation phase (PND 81), mice ( $n=10$ per group) were placed in the center of the empty box and allowed to explore it freely for $2 \mathrm{~min}$. Twenty-four hours later (PND 82), at T1, subjects were introduced for $3 \mathrm{~min}$ in the box, which contained the stones each placed in opposite corners. Following this, the mice were returned to their home cage for $1 \mathrm{~min}$ (memory retention interval). For T2, we replaced one of the stones with a toy and, after the memory retention interval, the animals were placed once again in the box for another $3 \mathrm{~min}$ to evaluate their exploration of the novel object. Object exploration was defined as intentional contact of the mouse's snout or front paws with the object from a distance of $2 \mathrm{~cm}$ or less. The following behaviors were scored: sum of the total time ( $t$, seconds) spent exploring the two stones at $\mathrm{T} 1$, sum of the time spent exploring the stone and the toy at $\mathrm{T} 2$, and the difference between the time spent exploring the stone and the toy at T2. The basic measure of memory acquisition was the discrimination index $(\mathrm{DI})$, calculated as: DI $=\left(t_{\text {novel }}-t_{\text {familiar }}\right) /\left(t_{\text {novel }}+t_{\text {familiar }}\right) \times 100 \%$ [84].

\subsubsection{Elevated Plus Maze}

The elevated plus maze (EPM) paradigm is based on the natural aversion of mice to open elevated areas, and also on the natural spontaneous exploratory behavior they exhibit in novel environments. It measures the extent to which the rodents avoid high open spaces. In our experiment it consisted of two open arms $\left(30 \times 5 \mathrm{~cm}^{2}\right)$ and two enclosed arms $\left(30 \times 5 \mathrm{~cm}^{2}\right)$, and the junction of the four arms formed a central platform $\left(5 \times 5 \mathrm{~cm}^{2}\right)$. The floor of the maze was made of black plexiglas and the walls of the closed arms were made of clear plexiglas. The open arms had a small edge $(0.25 \mathrm{~cm})$ to provide the animals with additional grip. The entire apparatus was elevated $45 \mathrm{~cm}$ above floor level. The total time spent in the open and closed arms, the number of entries into the open and closed arms, and the percentage of time and entries in the open arms are commonly considered indicators of open space-induced anxiety in mice. The total entries in both arms and the time spent in the center are regarded as locomotor activity scores (for more details, $[85,86]$ ).

At the beginning of each trial (PND 82), subjects $(n=10)$ were placed on the central platform of the EPM and were allowed to explore it for $5 \mathrm{~min}$. The behavior displayed by the mice was video recorded and the following measurements were taken into account for the statistical analyses: total time spent in the open arms (Time OA), percentage of time in the OA (\% time OA), number of entries into the OA (OA entries), percentage of entries into the OA (\% entries OA), total time spent in the closed arms (Time CA), number of entries into the CA (CA entries), total entries, and total time spent on the central platform (Time center).

\subsubsection{Tail Suspension}

The tail suspension test (TST) measures the behavioral variable of immobility, which is considered to represent despair [87]. It is based on the observation that rodents, after initial escape-oriented movements, develop an immobile posture when placed in an inescapable stressful situation. In the case of the TST, the stressful situation involves the hemodynamic stress of being hung in an uncontrollable fashion by their tail [88]. This has been used as a measure of behavioral depression because, when antidepressant treatments are given prior to the test, the subjects will engage in escape-directed behaviors for longer periods of time than after treatment with the vehicle [88].

Following the protocol described by [89], on PND 83 adhesive tape was used to suspend mice ( $n=10$ per group) by the tail from a hook connected to a strain gauge that recorded their movements during a 6-min test period. The behavior displayed by the mice was video recorded and the parameter considered for the statistical analyses was the total time spent immobile. 
The order of the different tests undergone by the mice was selected based on pilot studies conducted in our laboratory that demonstrated the absence of any influence of previous testing on the subsequent test. As the TST is the most stressing, it was performed last. In a previous study [55] we have used a slightly different schedule of behavioral testing obtaining the same results in control mice. A schematic description of the experimental procedure is provided in Table 2.

Table 2. Summary of the experimental design.

\begin{tabular}{clcccccccc}
\hline & \multicolumn{4}{c}{ Treatment } & \multicolumn{4}{c}{ Behavioral Testing } \\
\hline \multirow{2}{*}{ PND } & $34-47$ & $48-67$ & $68-69$ & $70-72$ & $75-79$ & 80 & 81 & 82 & 83 \\
\hline \multirow{3}{*}{ Group } & SAL & & SAL & SAL & SAL & & & & \\
& SAL & COCA 5 & COCA 15 & COCA 25 & OF & PPI & OR & TST \\
& WIN & & SAL & SAL & SAL & PPI & OR & EPM & \\
& WIN & COCA 5 & COCA 15 & COCA 25 & & & & \\
\hline
\end{tabular}

$\overline{\mathrm{PND}}=$ Postnatal day; WIN = WIN 55212-2 $(0.5 \mathrm{mg} / \mathrm{kg})$ injected once a day during 14 consecutive days; COCA $=$ cocaine given for three daily injections separated by a $60 \mathrm{~min}$ interval by the ensuing regime: $5 \mathrm{mg} / \mathrm{kg}$ on PND 68 and 69, $15 \mathrm{mg} / \mathrm{kg}$ on PND 70, 71 and 72, a 2 days abstinence period, and $25 \mathrm{mg} / \mathrm{kg}$ on PND 75, 76, 77, 78 and 79; $\mathrm{SAL}=$ saline $(\mathrm{NaCl} 0.9 \% w / v)$ given at the same treatment conditions as WIN and cocaine depending on the group. The experimental groups constituted were: Sal-Sal, WIN-Sal, Sal-Coca, and WIN-Coca. Behavioral testing began on PND 80. OF = open field, $\mathrm{PPI}=$ prepulse inhibition, $\mathrm{OR}=$ object recognition, $\mathrm{EPM}=$ elevated plus maze, $\mathrm{TST}=$ tail suspension test. For more details see the Materials and Methods section.

\subsection{Statistical Analyses}

Data were analyzed by means of two-way ANOVA with two between-subjects variables: pre-treatment (with two levels: Sal and WIN) and treatment (with two levels: Sal and Coca), followed by Tukey's honest significant difference (HSD), a post hoc test that does not require a significant interaction between factors and is highly conservative against type I error [90]. The $\alpha$ level was set at $p<0.05$ for all analyses.

\section{Conclusions}

In summary, the current results demonstrate for the first time the long-lasting consequences of juvenile exposure to WIN on cocaine withdrawal in adult mice. In addition, we corroborate the long-term effects of adolescent WIN administration in the disruption of the PPI, and the deleterious effects of both WIN and cocaine on memory retention previously shown by others. The most important item of data derived from our experiments is that we found an interaction between prior WIN consumption during adolescence and later abstinence from cocaine, in anxiety- and depressive-like behaviors. Exposure to WIN during adolescence prevents the anxiety-like effects observed in mice withdrawn from cocaine in the EPM. Moreover, mice treated with WIN during adolescence showed a specific increase in depressive-like symptoms in the TST during cocaine abstinence. Therefore, it seems that adolescent cannabinoid exposure could modulate the vulnerability to suffer from different behavioral disturbances after later cocaine withdrawal. To verify this hypothesis more thoroughly and to strengthen the present results, it would be suitable in the future to carry out these same experiments using the CB1 receptor agonist WIN together with a CB1 antagonist.

Given that pubertal cannabis use followed by later cocaine abuse is an increasingly common pattern of drug consumption in human beings, the results of the present research are particularly relevant, as they provide evidence that this pattern of drug intake could alter some of the behavioral outcomes produced by these drugs when given alone. Moreover, the results of the present work link directly with those of an earlier report, showing that adolescent binge $\mathrm{EtOH}$ exposure also modulates cocaine withdrawal symptoms [56]. Therefore, taking into account the high incidence of the consumption of these drugs and the later development of cocaine addiction [28,35], it becomes indispensable to open up new pharmacological and therapeutic strategies to prevent their intake, 
focusing especially on adolescent subjects, who have proven to make up a very vulnerable population as regards suffering from drug-induced psychiatric alterations [11,55].

Acknowledgments: This work was supported by grants from the Ministerio de Economía y Competitividad (MINECO), Dirección General de Investigación, PSI2014-51847-R; MINECO, Proyecto I+D+i PSI2015-69649-R; Instituto de Salud Carlos III, Red de Trastornos Adictivos (RTA) RD12/0028/0005 and RD16/0017/0007; Unión Europea, Fondos FEDER "una manera de hacer Europa"; Ministerio de Sanidad, Servicios Sociales e Igualdad. Delegación del Gobierno para el Plan Nacional Sobre Drogas, Proyectos de Investigación sobre Drogodependencias, 2014I007. Juan Carlos Ledesma was supported by a postdoctoral fellowship from the Conselleria d'Educació, Investigació, Cultura i Esport (APOSTD/2016/147), Generalitat Valenciana, Spain. The authors are entirely responsible for the scientific content of the paper.

Author Contributions: Maria A. Aguilar, Marta Rodríguez-Arias and M. Carmen Arenas conceived and designed the experiments and were responsible for the interpretation of the results; Carles Penalva and Carmen Manzanedo performed the experiments; Juan Carlos Ledesma analyzed the data and wrote the first draft of the paper; Maria A. Aguilar and José Miñarro wrote the final version of the manuscript.

Conflicts of Interest: The authors declare no conflict of interest.

\section{References}

1. Substance Abuse Mental Health Services Administration. Results from the 2010 National Survey on Drug Use and Health: Summary of National Findings; DHHS: Rockville, MD, USA, 2011.

2. Lichtman, A.H.; Martin, B.R. $\Delta$ 9-tetrahydrocannabinol impairs spatial memory through a cannabinoid receptor mechanism. Psychopharmacology 1996, 126, 125-131. [CrossRef] [PubMed]

3. Munro, S.; Thomas, K.L.; Abu-Shaar, M. Molecular characterization of a peripheral receptor for cannabinoids. Nature 1993, 365, 61-65. [CrossRef] [PubMed]

4. EMCDDA-European Monitoring Centre for Drugs and Drug Addiction. European Drug Report 2016: Trends and Developments; Publications Office of the European Union: Luxembourg, 2016; ISBN 978-92-9168-890-6. [CrossRef]

5. Pertwee, R.G. Cannabinoid receptor ligands: Clinical and neuropharmacological considerations, relevant to future drug discovery and development. Expert Opin. Investig. Drugs 2000, 9, 1553-1571. [CrossRef] [PubMed]

6. Sagheddu, C.; Melis, M. Individual differences and vulnerability to drug addiction: A focus on the endocannabinoid system. CNS Neurol. Disord. Drug Targets 2015, 14, 502-517. [CrossRef] [PubMed]

7. Tan, H.; Ahmad, T.; Loureiro, M.; Zunder, J.; Laviolette, S.R. The role of cannabinoid transmission in emotional memory formation: Implications for addiction and schizophrenia. Front. Psychiatry 2014, 5, 73. [CrossRef] [PubMed]

8. Chadwick, B.; Miller, M.L.; Hurd, Y.L. Cannabis use during adolescent development: Susceptibility to psychiatric illness. Front. Psychiatry 2013, 4, 129. [CrossRef] [PubMed]

9. Hayatbakhsh, M.R.; Najman, J.M.; Jamrozik, K.; Mamun, A.A.; Alati, R.; Bor, W. Cannabis and anxiety and depression in young adults: A large prospective study. J. Am. Acad. Child. Adolesc. Psychiatry 2007, 46, 408-417. [CrossRef] [PubMed]

10. Meier, M.H.; Caspi, A.; Ambler, A.; Harrington, H.; Houts, R.; Keefe, R.S.; McDonald, K.; Ward, A.; Poulton, R.; Moffitt, T.E. Persistent cannabis users show neuropsychological decline from childhood to midlife. Proc. Natl. Acad. Sci. USA 2012, 109, E2657-E2664. [CrossRef] [PubMed]

11. Renard, J.; Krebs, M.O.; le Pen, G.; Jay, T.M. Long-term consequences of adolescent cannabinoid exposure in adult psychopathology. Front. Neurosci. 2014, 8, 361. [CrossRef] [PubMed]

12. Realini, N.; Rubino, T.; Parolaro, D. Neurobiological alterations at adult age triggered by adolescent exposure to cannabinoids. Pharmacol. Res. 2009, 60, 132-138. [CrossRef] [PubMed]

13. Renard, J.; Rushlow, W.J.; Laviolette, S.R. What can rats tell us about adolescent cannabis exposure? Insights from preclinical research. Can. J. Psychiatry 2016, 61, 328-334. [PubMed]

14. Gleason, K.A.; Birnbaum, S.G.; Shukla, A.; Ghose, S. Susceptibility of the adolescent brain to cannabinoids: Long-term hippocampal effects and relevance to schizophrenia. Transl. Psychiatry 2012, 2, e199. [CrossRef] [PubMed] 
15. Tomas-Roig, J.; Benito, E.; Agis-Balboa, R.C.; Piscitelli, F.; Hoyer-Fender, S.; di Marzo, V.; Havemann-Reinecke, U. Chronic exposure to cannabinoids during adolescence causes long-lasting behavioral deficits in adult mice. Addict. Biol. 2016. [CrossRef] [PubMed]

16. Schneider, M.; Koch, M. Chronic pubertal, but not adult chronic cannabinoid treatment impairs sensorimotor gating, recognition memory, and the performance in a progressive ratio task in adult rats. Neuropsychopharmacology 2003, 28, 1760-1769. [CrossRef] [PubMed]

17. Wegener, N.; Koch, M. Behavioural disturbances and altered Fos protein expression in adult rats after chronic pubertal cannabinoid treatment. Brain Res. 2009, 1253, 81-91. [CrossRef] [PubMed]

18. Bortolato, M.; Bini, V.; Frau, R.; Devoto, P.; Pardu, A.; Fan, Y.; Solbrig, M.V. Juvenile cannabinoid treatment induces frontostriatal gliogenesis in Lewis rats. Eur. Neuropsychopharmacol. 2014, 24, 974-985. [CrossRef] [PubMed]

19. Gomes, F.V.; Guimarães, F.S.; Grace, A. Effects of pubertal cannabinoid administration on attentional set-shifting and dopaminergic hyper-responsivity in a developmental disruption model of schizophrenia. Int. J. Neuropsychopharmacol. 2014, 18, 2. [CrossRef] [PubMed]

20. Bambico, F.R.; Nguyen, N.T.; Katz, N.; Gobbi, G. Chronic exposure to cannabinoids during adolescence but not during adulthood impairs emotional behaviour and monoaminergic neurotransmission. Neurobiol. Dis. 2010, 37, 641-655. [CrossRef] [PubMed]

21. Raver, S.M.; Keller, A. Permanent suppression of cortical oscillations in mice after adolescent exposure to cannabinoids: Receptor mechanisms. Neuropharmacology 2014, 86, 161-173. [CrossRef] [PubMed]

22. Zhang, X.; Feng, Z.J.; Chergui, K. Induction of cannabinoid- and N-methyl-D-aspartate receptor-mediated long-term depression in the nucleus accumbens and dorsolateral striatum is region and age dependent. Int. J. Neuropsychopharmacol. 2015, 18, 4. [CrossRef] [PubMed]

23. Abush, H.; Akirav, I. Short- and long-term cognitive effects of chronic cannabinoids administration in late-adolescence rats. PLoS ONE 2012, 7, e31731. [CrossRef] [PubMed]

24. Kirschmann, E.K.; Pollock, M.W.; Nagarajan, V.; Torregrossa, M.M. Effects of adolescent cannabinoid self-administration in rats on addiction-related behaviors and working memory. Neuropsychopharmacology 2017, 42, 989-1000. [CrossRef] [PubMed]

25. Cass, D.K.; Flores-Barrera, E.; Thomases, D.R.; Vital, W.F.; Caballero, A.; Tseng, K.Y. CB1 cannabinoid receptor stimulation during adolescence impairs the maturation of GABA function in the adult rat prefrontal cortex. Mol. Psychiatry 2014, 19, 536-543. [CrossRef] [PubMed]

26. Candelaria-Cook, F.T.; Hamilton, D.A. Chronic cannabinoid agonist (WIN 55,212-2) exposure alters hippocampal dentate gyrus spine density in adult rats. Brain Res. 2014, 1542, 104-110. [CrossRef] [PubMed]

27. Degenhardt, L.; Hall, W.; Lynskey, M. The relationship between cannabis use and other substance use in the general population. Drug Alcohol Depend. 2001, 64, 319-327. [CrossRef]

28. Kandel, D.B.; Yamaguchi, K.; Klein, L.C. Testing the Gateway Hypothesis. Addiction 2006, 101, 470-472. [PubMed]

29. Kandel, D.; Kandel, E. The Gateway Hypothesis of substance abuse: Developmental, biological and societal perspectives. Acta Paediatr. 2015, 104, 130-137. [CrossRef] [PubMed]

30. Pistis, M.; Perra, S.; Pillolla, G.; Melis, M.; Muntoni, A.L.; Gessa, G.L. Adolescent exposure to cannabinoids induces long-lasting changes in the response to drugs of abuse of rat midbrain dopamine neurons. Biol. Psychiatry 2004, 56, 86-94. [CrossRef] [PubMed]

31. Ellgren, M.; Hurd, Y.; Franck, J. Amphetamine effects on dopamine levels and behavior following cannabinoid exposure during adolescence. Eur. J. Pharmacol. 2004, 497, 205-213. [CrossRef] [PubMed]

32. Rodríguez-Arias, M.; Manzanedo, C.; Roger-Sánchez, C.; do Couto, B.R.; Aguilar, M.A.; Miñarro, J. Effect of adolescent exposure to WIN 55212-2 on the acquisition and reinstatement of MDMA-induced conditioned place preference. Prog. Neuropsychopharmacol. Biol. Psychiatry 2010, 34, 166-171. [CrossRef] [PubMed]

33. Byrnes, J.J.; Johnson, N.L.; Schenk, M.E.; Byrnes, E.M. Cannabinoid exposure in adolescent female rats induces transgenerational effects on morphine conditioned place preference in male offspring. J. Psychopharmacol. 2012, 26, 1348-1354. [CrossRef] [PubMed]

34. Vassoler, F.M.; Johnson, N.L.; Byrnes, E.M. Female adolescent exposure to cannabinoids causes transgenerational effects on morphine sensitization in female offspring in the absence of in utero exposure. J. Psychopharmacol. 2013, 27, 1015-1022. [CrossRef] [PubMed] 
35. Arias, F.; Szerman, N.; Vega, P.; Mesias, B.; Basurte, I.; Morant, C.; Ochoa, E.; Poyo, F.; Babin, F. Cocaine abuse or dependency and other psychiatric disorders. Madrid study on dual pathology. Rev. Psiquiatr. Salud. Ment. 2013, 6, 121-128. [CrossRef] [PubMed]

36. Arias, F.; Szerman, N.; Vega, P.; Mesias, B.; Basurte, I.; Morant, C.; Ochoa, E.; Poyo, F.; Babin, F. Abuse or dependence on cannabis and other psychiatric disorders. Madrid study on dual pathology prevalence. Actas Esp. Psiquiatr. 2013, 41, 122-129. [PubMed]

37. EMCDDA-European Monitoring Centre for Drugs and Drug Addiction. European Drug Report: Trends and Developments; Publications Office of the European Union: Luxembourg, 2014; ISBN 978-92-9168-694-0. [CrossRef]

38. Rodríguez-Arias, M.; Roger-Sánchez, C.; Vilanova, I.; Revert, N.; Manzanedo, C.; Miñarro, J.; Aguilar, M.A. Effects of cannabinoid exposure during adolescence on the conditioned rewarding effects of WIN 55212-2 and cocaine in mice: Influence of the novelty-seeking trait. Neural Plast. 2016, 2016, 6481862. [CrossRef] [PubMed]

39. Deroche-Gamonet, V.; Piazza, P.V. Psychobiology of cocaine addiction: Contribution of a multi-symptomatic animal model of loss of control. Neuropharmacology 2014, 76, 437-449. [CrossRef] [PubMed]

40. Craige, C.P.; Lewandowski, S.; Kirby, L.G.; Unterwald, E.M. Dorsal raphe 5-HT2c receptor and GABA networks regulate anxiety produced by cocaine withdrawal. Neuropharmacology 2015, 93, 41-51. [CrossRef] [PubMed]

41. Dalley, J.W.; Lääne, K.; Pena, Y.; Theobald, D.E.; Everitt, B.J.; Robbins, T.W. Attentional and motivational deficits in rats withdrawn from intravenous self-administration of cocaine or heroin. Psychopharmacology 2005, 182, 579-587. [CrossRef] [PubMed]

42. Perrine, S.A.; Sheikh, I.S.; Nwaneshiudu, C.A.; Schroeder, J.A.; Unterwald, E.M. Withdrawal from chronic administration of cocaine decreases $\Delta$ opioid receptor signaling and increases anxiety- and depression-like behaviors in the rat. Neuropharmacology 2008, 54, 355-364. [CrossRef] [PubMed]

43. Tang, Y.; Martin, N.L.; Cotes, R.O. Cocaine-induced psychotic disorders: Presentation, mechanism, and management. J. Dual Diagn. 2014, 10, 98-105. [CrossRef] [PubMed]

44. Schoenbaum, G.; Saddoris, M.P.; Ramus, S.J.; Shaham, Y.; Setlow, B. Cocaine-experienced rats exhibit learning deficits in a task sensitive to orbitofrontal cortex lesions. Eur. J. Neurosci. 2004, 19, 1997-2002. [CrossRef] [PubMed]

45. Mateos-García, A.; Roger-Sánchez, C.; Rodriguez-Arias, M.; Miñarro, J.; Aguilar, M.A.; Manzanedo, C.; Arenas, M.C. Higher sensitivity to the conditioned rewarding effects of cocaine and MDMA in High-Novelty-Seekers mice exposed to a cocaine binge during adolescence. Psychopharmacology 2015, 232, 101-113. [CrossRef] [PubMed]

46. Manzanedo, C.; Aguilar, M.A.; Rodríguez-Arias, M.; Navarro, M.; Miñarro, J. Cannabinoid agonist-induced sensitisation to morphine place preference in mice. Neuroreport 2004, 15, 1373-1377. [CrossRef] [PubMed]

47. Manzanedo, C.; Rodríguez-Arias, M.; Daza-Losada, M.; Maldonado, C.; Aguilar, M.A.; Miñarro, J. Effect of the CB1 cannabinoid agonist WIN 55212-2 on the acquisition and reinstatement of MDMA-induced conditioned place preference in mice. Behav. Brain Funct. 2010, 6, 19. [CrossRef] [PubMed]

48. Daza-Losada, M.; Miñarro, J.; Aguilar, M.A.; Valverde, O.; Rodríguez-Arias, M. Acute blockade of CB1 receptor leads to reinstatement of MDMA-induced conditioned place preference. Pharmacol. Biochem. Behav. 2011, 100, 33-39. [CrossRef] [PubMed]

49. Castro, C.A.; Hogan, J.B.; Benson, K.A.; Shehata, C.W.; Landauer, M.R. Behavioral effects of vehicles: DMSO, ethanol, Tween-20, Tween-80, and emulphor-620. Pharmacol. Biochem. Behav. 1995, 50, 521-526. [CrossRef]

50. Maldonado, R. Study of cannabinoid dependence in animals. Pharmacol. Ther. 2002, 95, 153-164. [CrossRef]

51. Zawilska, J.B.; Wojcieszak, J. Spice/K2 drugs-More than innocent substitutes for marijuana. Int. J. Neuropsychopharmacol. 2014, 17, 509-525. [CrossRef] [PubMed]

52. Ksir, C.; Hart, C.L. Cannabis and psychosis: A critical overview of the relationship. Psychiatry Rep. 2016, 18, 12. [CrossRef] [PubMed]

53. Adams, J.U.; Efferen, T.R.; Duncan, E.J.; Rotrosen, J. Prepulse inhibition of the acoustic startle response in cocaine-withdrawn rats. Pharmacol. Biochem. Behav. 2001, 68, 753-759. [CrossRef]

54. Murphy, C.A.; di Iorio, L.; Feldon, J. Effects of psychostimulant withdrawal on latent inhibition of conditioned active avoidance and prepulse inhibition of the acoustic startle response. Psychopharmacology 2001, 156, 155-164. [CrossRef] [PubMed] 
55. Ledesma, J.C.; Aguilar, M.A.; Giménez-Gómez, P.; Miñarro, J.; Rodríguez-Arias, M. Adolescent but not adult ethanol binge drinking modulates cocaine withdrawal symptoms in mice. PLoS ONE 2017, 12, e0172956. [CrossRef] [PubMed]

56. Raver, S.M.; Haughwout, S.P.; Keller, A. Adolescent cannabinoid exposure permanently suppresses cortical oscillations in adult mice. Neuropsychopharmacology 2013, 38, 2338-2347. [CrossRef] [PubMed]

57. O'Tuathaigh, C.M.; Hryniewiecka, M.; Behan, A.; Tighe, O.; Coughlan, C.; Desbonnet, L.; Cannon, M.; Karayiorgou, M.; Gogos, J.A.; Cotter, D.R.; et al. Chronic adolescent exposure to $\Delta$-9-tetrahydrocannabinol in COMT mutant mice: Impact on psychosis-related and other phenotypes. Neuropsychopharmacology 2010, 35, 2262-2273. [CrossRef] [PubMed]

58. Cadoni, C.; Simola, N.; Espa, E.; Fenu, S.; Di Chiara, G. Strain dependence of adolescent Cannabis influence on heroin reward and mesolimbic dopamine transmission in adult Lewis and Fischer 344 rats. Addict. Biol. 2015, 20, 132-142. [CrossRef] [PubMed]

59. Briand, L.A.; Gross, J.P.; Robinson, T.E. Impaired object recognition following prolonged withdrawal from extended-access cocaine self-administration. Neuroscience 2008, 155, 1-6. [CrossRef] [PubMed]

60. Morisot, N.; le Moine, C.; Millan, M.J.; Contarino, A. CRF1 receptor-deficiency reduces recognition memory deficits and vulnerability to stress induced by cocaine withdrawal. Int. J. Neuropsychopharmacol. 2014, 17, 1969-1979. [CrossRef] [PubMed]

61. Stopponi, S.; Soverchia, L.; Ubaldi, M.; Cippitelli, A.; Serpelloni, G.; Ciccocioppo, R. Chronic THC during adolescence increases the vulnerability to stress-induced relapse to heroin seeking in adult rats. Eur. Neuropsychopharmacol. 2014, 24, 1037-1045. [CrossRef] [PubMed]

62. Alves, C.J.; Magalhães, A.; Melo, P.; de Sousa, L.; Tavares, M.A.; Monteiro, P.R.; Summavielle, T. Long-term effects of chronic cocaine exposure throughout adolescence on anxiety and stress responsivity in a Wistar rat model. Neuroscience 2014, 277, 343-355. [CrossRef] [PubMed]

63. De Oliveira Citó Mdo, C.; da Silva, F.C.; Silva, M.I.; Moura, B.A.; Macêdo, D.S.; Woods, D.J.; Fonteles, M.M.; de Vasconcelos, S.M.; de Sousa, F.C. Reversal of cocaine withdrawal-induced anxiety by ondansetron, buspirone and propranolol. Behav. Brain Res. 2012, 231, 116-123. [PubMed]

64. El Hage, C.; Rappeneau, V.; Etievant, A.; Morel, A.L.; Scarna, H.; Zimmer, L.; Bérod, A. Enhanced anxiety observed in cocaine withdrawn rats is associated with altered reactivity of the dorsomedial prefrontal cortex. PLoS ONE 2012, 7, e43535. [CrossRef] [PubMed]

65. Hall, B.J.; Pearson, L.S.; Buccafusco, J.J. Effect of the use-dependent, nicotinic receptor antagonist BTMPS in the forced swim test and elevated plus maze after cocaine discontinuation in rats. Neurosci. Lett. 2010, 474, 84-87. [CrossRef] [PubMed]

66. Kupferschmidt, D.A.; Newman, A.E.; Boonstra, R.; Erb, S. Antagonism of cannabinoid 1 receptors reverses the anxiety-like behavior induced by central injections of corticotropin-releasing factor and cocaine withdrawal. Neuroscience 2012, 204, 125-133. [CrossRef] [PubMed]

67. Lejuez, C.W.; Zvolensky, M.J.; Daughters, S.B.; Bornovalova, M.A.; Paulson, A.; Tull, M.T.; Ettinger, K.; Otto, M.W. Anxiety sensitivity: A unique predictor of dropout among inner-city heroin and crack/cocaine users in residential substance use treatment. Behav. Res. Ther. 2008, 46, 811-818. [CrossRef] [PubMed]

68. Valzachi, M.C.; Teodorov, E.; Marcourakis, T.; Bailey, A.; Camarini, R. Enhancement of behavioral sensitization, anxiety-like behavior, and hippocampal and frontal cortical CREB levels following cocaine abstinence in mice exposed to cocaine during adolescence. PLoS ONE 2013, 8, e78317. [CrossRef] [PubMed]

69. Chartoff, E.; Sawyer, A.; Rachlin, A.; Potter, D.; Pliakas, A.; Carlezon, W.A. Blockade of kappa opioid receptors attenuates the development of depressive-like behaviors induced by cocaine withdrawal in rats. Neuropharmacology 2012, 62, 167-176. [CrossRef] [PubMed]

70. Zilkha, N.; Feigin, E.; Barnea-Ygael, N.; Zangen, A. Induction of depressive-like effects by subchronic exposure to cocaine or heroin in laboratory rats. J. Neurochem. 2014, 130, 575-582. [CrossRef] [PubMed]

71. Sweeney, F.F.; O'Leary, O.F.; Cryan, J.F. Activation but not blockade of GABAB receptors during early-life alters anxiety in adulthood in BALB/c mice. Neuropharmacology 2014, 81, 303-310. [CrossRef] [PubMed]

72. Grey, J.; Terry, P.; Higgs, S. Contrasting effects of different cannabinoid receptor ligands on mouse ingestive behaviour. Behav. Pharmacol. 2012, 23, 551-559. [CrossRef] [PubMed]

73. Linsenbardt, D.N.; Boehm, S.L. Agonism of the endocannabinoid system modulates binge-like alcohol intake in male C57BL/6J mice: Involvement of the posterior ventral tegmental area, 2nd. Neuroscience 2009, 164, 424-434. [CrossRef] [PubMed] 
74. Black, Y.D.; Maclaren, F.R.; Naydenov, A.V.; Carlezon, W.A., Jr.; Baxter, M.G.; Konradi, C. Altered attention and prefrontal cortex gene expression in rats after binge-like exposure to cocaine during adolescence. J. Neurosci. 2006, 26, 9656-9665. [CrossRef] [PubMed]

75. Fendt, M.; Koch, M. Translational value of startle modulations. Cell Tissue Res. 2013, 354, 287-295. [CrossRef] [PubMed]

76. Gobira, P.H.; Ropke, J.; Aguiar, D.C.; Crippa, J.A.; Moreira, F.A. Animal models for predicting the efficacy and side effects of antipsychotic drugs. Rev. Bras. Psiquiatr. 2013, 35. [CrossRef] [PubMed]

77. Powell, S.B.; Weber, M.; Geyer, M.A. Genetic models of sensorimotor gating: Relevance to neuropsychiatric disorders. Curr. Top. Behav. Neurosci. 2012, 12, 251-318. [PubMed]

78. Geyer, M.A.; McIlwain, K.L.; Paylor, R. Mouse genetic models for prepulse inhibition: An early review. Mol. Psychiatry 2002, 7, 1039-1053. [CrossRef] [PubMed]

79. Li, L.; Du, Y.; Li, N.; Wu, X.; Wu, Y. Top-down modulation of prepulse inhibition of the startle reflex in humans and rats. Neurosci. Biobehav. Rev. 2009, 33, 1157-1167. [CrossRef] [PubMed]

80. Van den Buuse, M. Modeling the positive symptoms of schizophrenia in genetically modified mice: Pharmacology and methodology aspects. Schizophr. Bull. 2010, 36, 246-270. [CrossRef] [PubMed]

81. Valsamis, B.; Schmid, S. Habituation and prepulse inhibition of acoustic startle in rodents. J. Vis. Exp. 2011, e3446. [CrossRef] [PubMed]

82. Ennaceur, A.; Delacour, J. A new one-trial test for neurobiological studies of memory in rats. 1: Behavioral data. Behav. Brain Res. 1988, 31, 47-59. [CrossRef]

83. Broadbent, N.J.; Squire, L.R.; Clark, R.E. Spatial memory, recognition memory, and the hippocampus. Proc. Natl. Acad. Sci. USA 2004, 101, 14515-14520. [CrossRef] [PubMed]

84. Montesinos, J.; Pascual, M.; Rodríguez-Arias, M.; Miñarro, J.; Guerri, C. Involvement of TLR4 in the long-term epigenetic changes, rewarding and anxiety effects induced by intermittent ethanol treatment in adolescence. Brain Behav. Immun. 2016, 53, 159-171. [CrossRef] [PubMed]

85. Campos, A.C.; Fogaça, M.V.; Aguiar, D.C.; Guimarães, F.S. Animal models of anxiety disorders and stress. Rev. Bras. Psiquiatr. 2013, 35, S101-S111. [CrossRef] [PubMed]

86. Rodríguez-Arias, M.; Vaccaro, S.; Arenas, M.C.; Aguilar, M.A.; Miñarro, J. The novelty-seeking phenotype modulates the long-lasting effects of adolescent MDMA exposure. Physiol. Behav. 2015, 141, 190-198. [CrossRef] [PubMed]

87. Pollak, D.D.; Rey, C.E.; Monje, F.J. Rodent models in depression research: Classical strategies and new directions. Ann. Med. 2010, 42, 252-264. [CrossRef] [PubMed]

88. Cryan, J.F.; Mombereau, C.; Vassout, A. The tail suspension test as a model for assessing antidepressant activity: Review of pharmacological and genetic studies in mice. Neurosci. Biobehav. Rev. 2005, 29, 571-625. [CrossRef] [PubMed]

89. Vaugeois, J.M.; Passera, G.; Zuccaro, F.; Costentin, J. Individual differences in response to imipramine in the mouse tail suspension test. Psychopharmacology 1997, 134, 387-391. [CrossRef] [PubMed]

90. Wilcox, R.R. New desings in analysis of variance. Annu. Rev. Psychol. 1987, 38, 29-60. [CrossRef]

(C) 2017 by the authors. Licensee MDPI, Basel, Switzerland. This article is an open access article distributed under the terms and conditions of the Creative Commons Attribution (CC BY) license (http:/ / creativecommons.org/licenses/by/4.0/). 